\title{
A new method to identify flanking sequence tags in chlamydomonas using 3'-RACE
}

\author{
Laurence Meslet-Cladière ${ }^{1}$ and Olivier Vallon ${ }^{2,3^{*}}$
}

\begin{abstract}
Background: The green alga Chlamydomonas reinhardtii, although a premier model organism in biology, still lacks extensive insertion mutant libraries with well-identified Flanking Sequence Tags (FSTs). Rapid and efficient methods are needed for FST retrieval.

Results: Here, we present a novel method to identify FSTs in insertional mutants of Chlamydomonas. Transformants can be obtained with a resistance cassette lacking a $3^{\prime}$ untranslated region (UTR), suggesting that the RNA that is produced from the resistance marker terminates in the flanking genome when it encounters a cleavage/ polyadenylation signal. We have used a robust 3'-RACE method to specifically amplify such chimeric cDNAs. Out of 38 randomly chosen transformants, 27 (71\%) yielded valid FSTs, of which 23 could be unambiguously mapped to the genome. Eighteen of the mutants lie within a predicted gene. All but two of the intragenic insertions occur in the sense orientation with respect to transcription, suggesting a bias against situations of convergent transcription. Among the 14 insertion sites tested by genomic PCR, 12 could be confirmed. Among these are insertions in genes coding for PSBS3 (possibly involved in non-photochemical quenching), the NimA-related protein kinase CNK2, the mono-dehydroascorbate reductase MDAR1, the phosphoglycerate mutase PGM5 etc..
\end{abstract}

Conclusion: We propose that our 3'-RACE FST method can be used to build large scale FST libraries in Chlamydomonas and other transformable organisms.

Keywords: Chlamydomonas, Transformation, Mutant library, 3' UTR, Antibiotic resistance

\section{Background}

In advanced genetic models like the green alga Chlamydomonas reinhardtii [1], the study of mutants is a powerful tool to elucidate the function of genes. In forward genetics, the genes of interest are a priori unknown, and mutants of interest are selected or screened for, based on the alteration of the function under study. In reverse genetics, genes relevant to the function are first identified based on their sequence or genome localization, and the challenge is to obtained mutants in these genes. In both approaches, insertion mutagenesis is the primary method, because it links to the interrupted gene a DNA fragment

\footnotetext{
* Correspondence: ovallon@ibpc.fr

${ }^{2}$ Present address : Centre National de la Recherche Scientifique, Unité Mixte de Recherche 7139/Université Pierre et Marie Curie, Station Biologique de Roscoff, Roscoff 29280, France

${ }^{3}$ Unité Mixte de Recherche 7141/Université Pierre et Marie Curie, Institut de Biologie Physico-Chimique Institut de Biologie Physico-Chimique, 13 rue Pierre et Marie Curie, Paris 75005, France

Full list of author information is available at the end of the article
}

(usually containing an antibiotic resistance marker) that then serves as a molecular tag of the mutation [2]. The next step is to obtain a piece of DNA that contains the junction between the marker and the host gene, and sequence it. This "Flanking Sequence Tag" (FST) identifies the genomic location of the insertion, its orientation and, if both borders are retrieved, the length of any deletion that may have occurred in the genome. If this approach is to be carried out on a whole genome scale, which is a natural ambition as soon as a model system enters the postgenomic era, a rapid, robust and cheap method is required.

Semi-degenerate PCR is the most popular technique for FST determination. For example in the reference land plant Arabidopsis thaliana, Thermal Asymmetric InterLaced PCR (TAIL-PCR) [3] is performed using a marker-specific primer and a degenerate primer that will anneal at random in the genome. This has allowed the development of vast libraries of insertional mutants, 
with tens of thousands of individual lines now available for public use. In recent years, Ligation-Mediated PCR has replaced TAIL-PCR for Arabidopsis [4] and is now applied to other organisms [5]. In Chlamydomonas, TAIL-PCR has been used to analyze the first mutant library of significant scale [6], as well as individual mutants (for example, [7]). Other PCR-based techniques relying on degenerate primers, such as RESDA-PCR [8] or SiteFinding-PCR [9] have also been used successfully. Yet, many laboratories, including ours, have found that Chlamydomonas DNA is difficult to amplify using degenerate PCR techniques, probably because of the high GC content (65\%) of the genome. Ligation-based methods such as GenomeWalker PCR [10] or inverted PCR [11] have also been used. None of these methods is fully reliable and it is often necessary to try several before an FST is obtained. In the context of a large library screen, these techniques are all expected to leave a sizeable fraction of the insertion sites undetermined.

Our long term goal is to generate and store a large library of Chlamydomonas insertional mutants with known FSTs. In the present study, we present a new FST identification method that requires neither ligation nor the use of degenerate primers. Using a codon-adapted AadA marker [12] conferring resistance to spectinomycin (Sp), we have generated random insertions in the nuclear genome of Chlamydomonas reinhardtii. We have previously reported that the 3' UTR of RBCS2, present in the original construct, is not necessary for transformation [12]. In transformants obtained with a marker lacking a 3' UTR, a chimeric mRNA is generated that originates in the marker DNA and terminates in the flanking Chlamydomonas genome. We have generated a small collection of mutants. Using oligo-dT primed reverse transcription and nested PCR amplification, we have obtained genome-anchored FSTs from 23 transformants out of 38 randomly selected clones.

\section{Results}

Transformants obtained with a resistance cassette lacking a 3' UTR

In previous experiments, we have found that the CrAadA cassette yields high numbers of transformants when used as a restriction fragment that lacks the 3' UTR [12]. Here, we used a PCR-amplified fragment that contains the HSP70A-RBCS2 promoter combination [13] and the recoded AadA CDS but which ends 57 nt after the stop codon, thus lacking most of the RBCS2 3' UTR and the TGTAA signal that direct cleavage and polyadenylation of the mRNA (Figure 1). The purified PCR product was transformed into strain JEX1, either undigested or after digestion with the enzymes BsiWI or SnaBI (transformations \#2, \#3 and \#4, respectively), for which recognition sites had been introduced by PCR at both ends of the

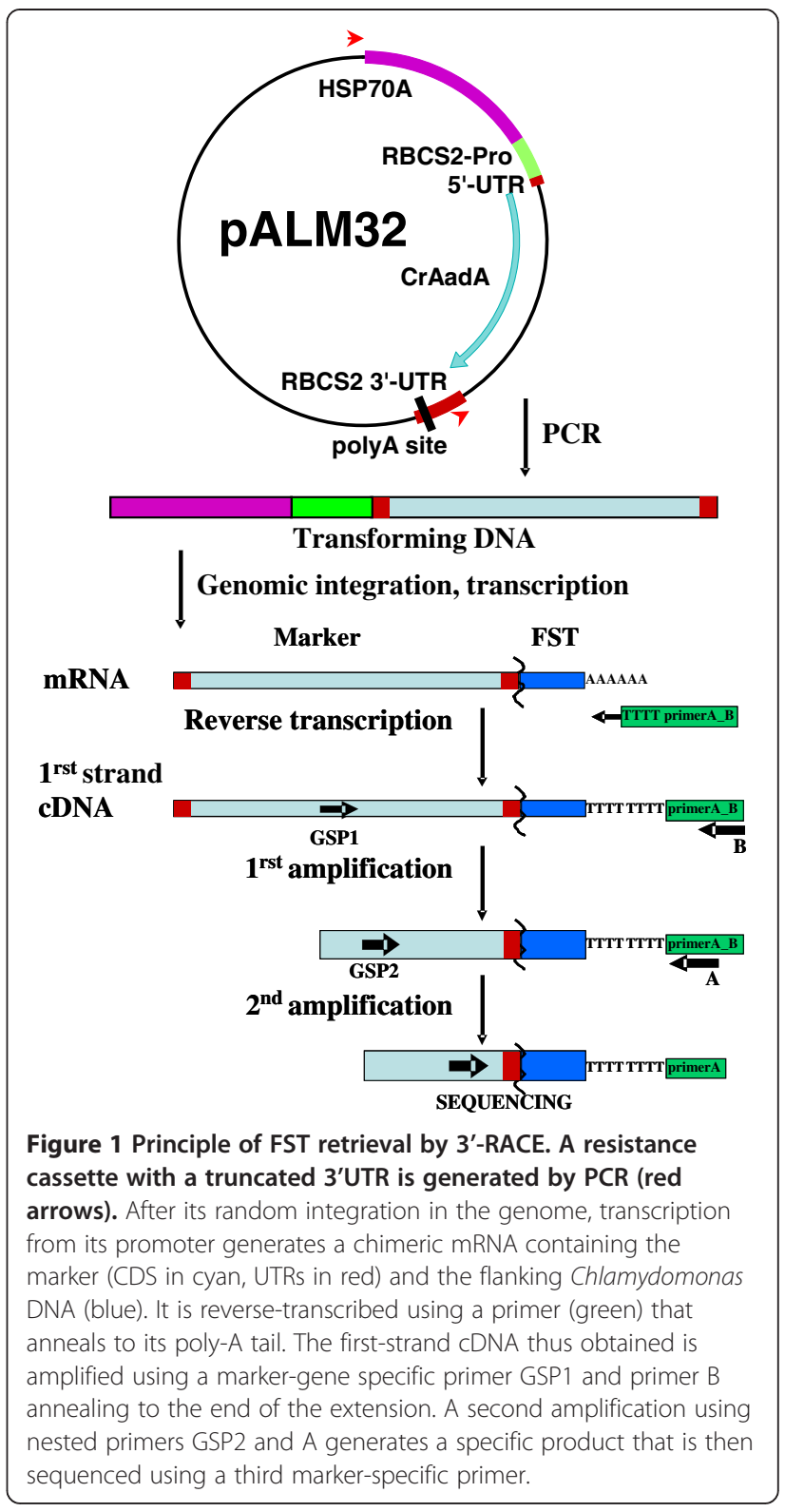

fragment (see Additional file 1). We also studied transformants obtained with the same PCR fragment digested by AatII (transformation \#11), which cleaves just before and just after the CDS, thus removing both the 3' UTR and the promoter. Finally, in order to check the validity of our method in other strains, we also transformed the cell-wall less strain D66 with the uncut PCR product (transformation \#14).

After plating on TAP plates containing Sp, we obtained approximatily 50 transformants per electroporation with the cassette lacking the 3'UTR (\#2, \#3, \#4 and \#14), compared to only 10 with the CDS alone (\#11) and about 100 with a control PCR product encompassing the full 3' UTR. For a given fragment, we saw no significant effect of the restriction enzyme digestion of the ends of the cassette 
on the transformation yield (data not shown). This shows that the nature of the DNA ends (recessed or blunt, phosphorylated or not) has little impact on transformation efficiency. For our FST-retrieval attempts, we randomly picked 38 transformants, ten from each of the transformations \#2, \#3 and \#4, and four from transformations \#11 and \#14. All of the transformants were resistant to $200 \mu \mathrm{g} / \mathrm{ml} \mathrm{Sp}$ initially, even if 3 eventually lost antibiotic resistance partially or completely after a year of propagation in the absence of the antibiotic. None of the transformants had obvious color or growth defects on TAP or Minimum medium.

\section{FST sequencing}

The resistance of the transformants to Sp suggests that a chimeric mRNA is formed that starts in the resistance marker and ends in the flanking DNA. Therefore, we prepared total RNA from transformants grown in liquid TAP in presence of antibiotic and performed RT-PCR using primer $\mathrm{Q}_{\mathrm{T}}$ (Figure 1). This primer anneals to the poly-A tail, yielding a first strand cDNA with a 35 nt 5' extension upstream of the oligo-dT. We then amplified the AadA cDNA using the marker-specific forward primer CrAadA_F1, and primer Qo which anneals to the first $18 \mathrm{nt}$ of the 5'-extension provided by $\mathrm{Q}_{\mathrm{T}}$. This first amplification (PCR1) usually resulted in only faint non- specific PCR products, similar in transformants and control strains (Figure 2). In a second, nested amplification (PCR2), we used a forward primer annealing further downstream in the marker,(CrAadA_F2) along with the reverse primer $\mathrm{Q}_{\mathrm{I}}$ annealing to the last $18 \mathrm{nt}$ of the $\mathrm{Q}_{\mathrm{T}}$ extension, downstream of $\mathrm{Q}_{\mathrm{o}}$. This time, we obtained PCR products of different sizes (Figure 2, top panel) suggesting that they arose from specific amplification of chimeric mRNAs, which we subsequently confirmed (see below). As a control, we also analyzed 3 transformants obtained with a longer PCR fragment that contained the entire RBCS2 3' UTR (see Additional file 1, p. 1) and found that the expected product was already visible after the first amplification. Sequencing of the 360 nt PCR2 product revealed the expected fusion between the CrAadA marker and the downstream RBCS2 3' UTR (Additional file 1). The yield of this product was not increased by a $30 \mathrm{~min} 40{ }^{\circ} \mathrm{C}$ heat shock (not shown), therefore we did not include this step in our routine protocol for analysis of transformants. Still, enhanced transcription after heat shock [13] could be beneficial for obtaining some products that are difficult to amplify. As a control for the quality of our RNA preparation and PCR method, we verified that all control and transformant samples produced strong amplification at PCR2 when the CrAadA primers were replaced by primers

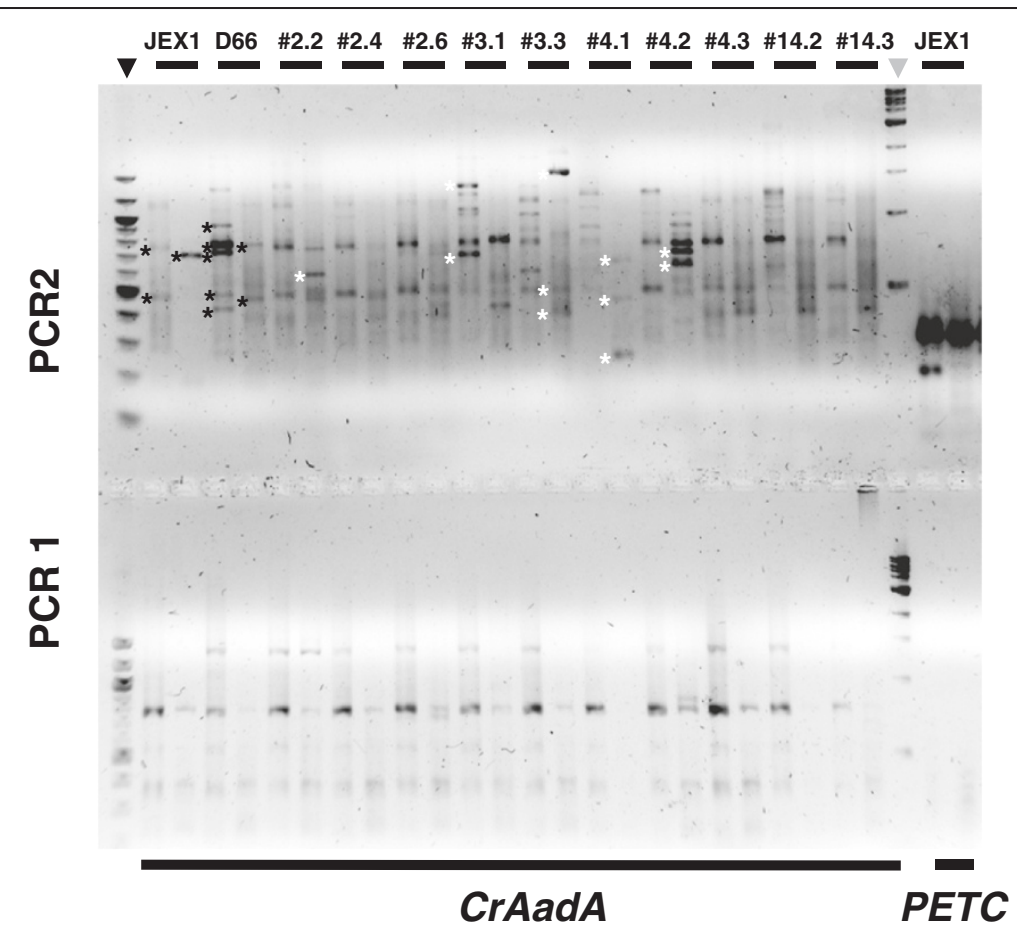

Figure 2 3'-RACE amplification of flanking DNA. Strains are indicated at the top. Regular Phusion polymerase was used to amplify the CrAadA marker (left) or the control PETC transcript (right). Bottom panel: PCR1; top: PCR2. The New England Biolabs size ladders are indicated by arrowheads (black: 100 bp ladder; grey: 1 kb ladder). Black stars point to background bands found in negative controls, white stars to mutant-specific bands that eventually yielded FSTs. For each strain, the left lane shows samples where PCR used annealing at $60{ }^{\circ} \mathrm{C}$, while the right lane used «touch down» from 72 to $60^{\circ} \mathrm{C}$ in 12 cycles. Note that the latter yields less background and in general stronger specific bands. 
annealing to the 3' UTR of the highly expressed endogenous PETC gene (Figure 2). The CrAadA amplification gave weaker bands, suggesting an overall lower level of expression.

As we were trying to establish a method of general applicability, we did not try to optimize the PCR conditions for every strain, but rather aimed to find conditions that would yield the highest amount of information from the group of transformants under study. We found that touch-down PCR for both the initial and the nested PCR improved the yield of mutant-specific bands (Figure 2), and that the use of HotStart Phusion polymerase gave more reproducible results than regular Phusion (compare Figure 3 and Figure 2). Initially, we carried out a third round of amplification using $\mathrm{Q}_{\mathrm{I}}$ and another marker-specific primer, CrAadA_F3, but we found that this in general did not improve the quality of the FST. Sequencing was done commercially using the Sanger dideoxynucleotide method. In our first experiments, we endeavored to separate the PCR2 or PCR3 products on agarose gels and the extracted DNA was sent for sequencing. However, interpretable results could also be obtained when the PCR product was sent directly for sequencing, even when multiple bands were observed on agarose gels (see below). In this case, it was sometimes necessary to analyze the chromatograms individually to disentangle overlapping sequences. At a late stage in the development of the method, we used for the 3 ' end a different set of primers, mimicking the Illumina adapter $\left(\mathrm{Q}_{\mathrm{S}}, \mathrm{Q}_{\mathrm{U}}\right.$ and $\mathrm{Q}_{\mathrm{D}}$, set 2, see Additional file 1), in combination with the same marker-specific primers (Figure 3). This slightly improved the efficiency of FST determination for strains that had initially failed, and we now recommend this set as more robust.

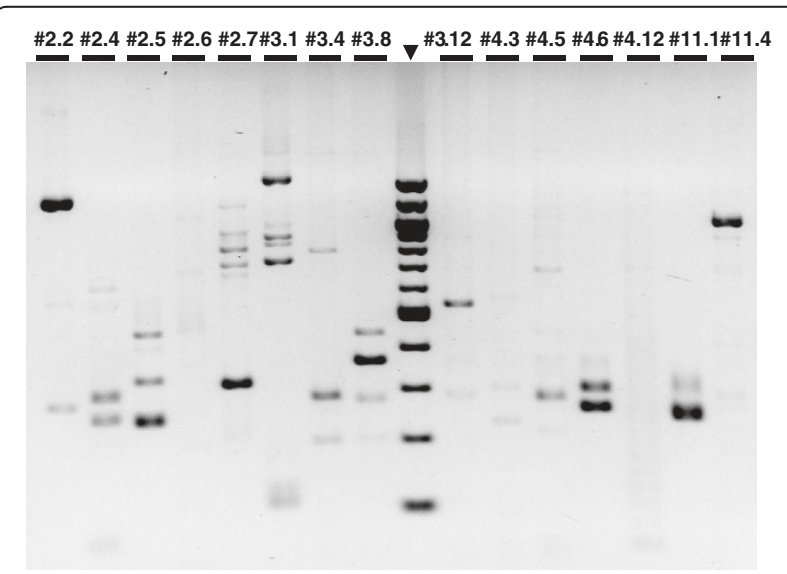

Figure 3 3'-RACE amplification of flanking DNA (PCR2). Strains are indicated at the top. Hot Start Phusion polymerase and primer set 2 were used in a touch-down PCR reaction. The $100 \mathrm{bp}$ ladder is indicated by an arrowhead.
Table 1 and Additional file 1 describe the FSTs obtained, from a total of 10 experiments grouping 3 to 22 transformants each. Each transformant was subjected to 1, 2, or a maximum of 3 sequencing attempts. In the end, we were able to obtain 28 valid FSTs from 27 of our 38 transformants (71\%). A sequence was considered as a valid FST when sequence continuity could be established between the cassette and more than $30 \mathrm{nt}$ of surrounding Chlamydomonas DNA (NB: continuity was not required for transformation \#11 where the AatII restriction site used is so close to the sequencing primer that we do not expect to be able to read the junction). Sequences were considered Failures when there were : absence of specific bands; sequence of low quality or lacking a recognizable marker portion; very short FSTs caused by premature polyadenylation; or PCR contamination from the control transformants carrying the full RBCS2 3' UTR. Some strains gave rise to multiple poly-A tracts, or to multiple bands yielding staggered FSTs pointing to the same genomic location, indicating that polyadenylation happened at multiple sites along the chimeric transcript. Transformant \#2.1 yielded two completely different FSTs, suggesting two independent insertions. In addition, several valid FSTs could not be mapped unambiguously to the Chlamydomonas genome, the most common reason being that they fell in a repeated sequence. The FST retrieved from transformant \#2.6 was composed of two transposable element fragments (DNA2-7_CR, followed by TOC1), a combination that is not found as such in the reference genome sequence. This suggests that either insertion of the marker activated a transposition event, or that the insertion locus lies in one of the sequence gaps of the genome. For transformant \#4.2, the FST could not be mapped onto version 4 of the genome, but it could be mapped to a partially finished version 5 , kindly communicated to us by Jane Grimwood. In total, 23 FSTs could be mapped to a unique location in the genome, while 5 remained of uncertain location. Among the mappable FTSs, four fell in intergenic regions, based on annotation of transcripts (Augustus 10.2). Of insertions into genes, one fell in a 5' UTR exon, five in 3 ' UTRs, three in coding exons and ten in introns.

\section{Verification by genomic PCR}

In order to independently verify that we had indeed determined the correct insertion site, we isolated crude genomic DNA from 19 of the transformants giving FSTs and subjected them to PCR, using primers designed to amplify the gene across the insertion point (Figure 4). The quality of each primer pair and each DNA preparation were checked using a positive control combination of strain and primer pair. Out of 13 tests where the expected control amplifications were obtained, we verified in 11 cases that the gene was indeed disrupted in the transformant. For two transformants, we found that 
Table 1 Summary of FST determination. Lines in italics indicate absence of valid FST

\begin{tabular}{|c|c|c|c|c|c|c|c|c|c|c|c|}
\hline $\begin{array}{l}\text { trans- } \\
\text { formant }\end{array}$ & $\begin{array}{l}\text { \# of } \\
\text { trials }\end{array}$ & $\begin{array}{l}\text { valid } \\
\text { FSTs }\end{array}$ & chromosome & $\begin{array}{l}\text { FST } \\
\text { position }\end{array}$ & locus & annotation & $\begin{array}{l}\text { type of } \\
\text { location }\end{array}$ & $\begin{array}{l}\text { orientation/ } \\
\text { gene }\end{array}$ & $\begin{array}{l}\text { marker } \\
\text { resection } \\
\text { (nt) }\end{array}$ & notes & $\begin{array}{l}\text { confirmation } \\
\text { by genomic PCR }\end{array}$ \\
\hline \multirow[t]{2}{*}{$\# 2.1$} & 3 & 2 & 16 & $304054-303727$ & $\begin{array}{l}\text { Cre16.g649785/ } \\
\text { Cre16.g649752 }\end{array}$ & $\begin{array}{l}\text { no predicted } \\
\text { function/ } \\
\text { no predicted } \\
\text { function }\end{array}$ & intergenic & not applicable & 9 & & unsure, $P C R$ failed \\
\hline & & 2 & 19 & $810984-811036$ & Cre19.g757350 & $\begin{array}{l}\text { NAC domain } \\
\text { protein }\end{array}$ & 3' UTR & + & 8 & $\begin{array}{l}\text { A } 37 \mathrm{nt} \text { fragment of the } \\
\text { PCR product is inserted } \\
\text { between the active cassette } \\
\text { and the flanking DNA; poly-A } \\
\text { site not recorded before for } \\
\text { the host gene }\end{array}$ & unsure, $P C R$ failed \\
\hline \#2.2 & 2 & 1 & 1 & $\begin{array}{l}8429714-8432270 \\
\text { (spliced) }\end{array}$ & Cre01.g060850 & $\begin{array}{l}\text { PSBS3, Chloroplast } \\
\text { PSII-associated } \\
22 \mathrm{kDa} \text { protein }\end{array}$ & $\begin{array}{l}\text { exon 3; FST } \\
\text { extends up to } \\
\text { exon 10, with } \\
\text { splicing }\end{array}$ & + & 0 & $\begin{array}{l}\text { expression of interrupted } \\
\text { gene is not documented } \\
\text { by } 454 \text { or Illumina data }\end{array}$ & confirmed \\
\hline \#2.3 & 2 & 1 & 12 & $589974-589850$ & Cre12.g488050 & $\begin{array}{l}\text { FFT5, Fructan } \\
\text { fructosyltransferase }\end{array}$ & intron 2 & - & 0 & & confirmed \\
\hline \#2.4 & 1 & 1 & 14 & $3326333-3326254$ & Cre14.g630200 & $\begin{array}{l}\text { no predicted } \\
\text { function }\end{array}$ & 3' UTR & + & 0 & $\begin{array}{l}\text { not the endogenous poly-A } \\
\text { site; part of the FST is hidden } \\
\text { below an early poly-A tail }\end{array}$ & $\begin{array}{l}\text { unsure, PCR } \\
\text { failed }\end{array}$ \\
\hline$\# 2.5$ & 3 & 2 & 12 & $\begin{array}{l}3269654-3269776 \\
\text { and divergent } \\
3268980-3269003\end{array}$ & Cre12.g512250 & $\begin{array}{l}\text { protein with } \\
\text { HRDC domain }\end{array}$ & intron 4 & + & 0 & $\begin{array}{l}\text { two staggered polyadenylation } \\
\text { sites }\end{array}$ & not tested \\
\hline \#2.6 & 1 & 1 & $?$ & $?$ & $?$ & $\begin{array}{l}\text { transposable } \\
\text { elements TOC1 } \\
\text { and DNA-2-7_CR }\end{array}$ & not applicable & not applicable & 0 & $\begin{array}{l}\text { UNMAPPED: could be in an } \\
\text { unsequenced region, or due } \\
\text { to a rearrangement }\end{array}$ & not tested \\
\hline$\# 2.7$ & 2 & 0 & - & & & & & & & $\begin{array}{l}\text { FAILED: amplifies a sequence } \\
\text { from Cre10.9429850 exon } \\
7 \text { but the junction with the } \\
\text { cassette } \\
\text { cannot be read }\end{array}$ & not tested \\
\hline$\# 2.8$ & 1 & 1 & 27 & 75383-75179 & Cre27.g774700 & SGNH hydrolase & 5'-UTR & + & $?$ & $\begin{array}{l}\text { poly-A tail at end of cassette } \\
\text { masks junction with flanking } \\
\text { DNA }\end{array}$ & confirmed \\
\hline$\# 2.9$ & 1 & 1 & 9 & $2341565-2341083$ & Cre09.g400950 & $\begin{array}{l}\text { Major Facilitator } \\
\text { Superfamilly }\end{array}$ & 3' UTR & + & 3 & uses endogenous poly-A site & confirmed \\
\hline \#2.11 & 2 & 1 & 17 & 1621018-1620917 & $\begin{array}{l}\text { Cre17.g707950/ } \\
\text { Cre17.g708000 }\end{array}$ & $\begin{array}{l}\text { HEP1 escort protein/ } \\
\text { PAS domain protein }\end{array}$ & intergenic & not applicable & 0 & $\begin{array}{l}\text { there are several other good } \\
\text { matches, but this is the only } \\
\text { perfect one }\end{array}$ & confirmed \\
\hline$\# 3.1$ & 3 & 0 & & & & & & & & $\begin{array}{l}\text { FAILED: no marker DNA } \\
\text { in sequence }\end{array}$ & - \\
\hline \#3.2 & 2 & 3 & 12 & 9166015-9166885 & Cre12.g560350 & $\begin{array}{l}\text { CNK2, NimA-related } \\
\text { protein kinase } 2\end{array}$ & $\begin{array}{l}\text { intron } 1 \\
\text { (splits 5'-UTR) }\end{array}$ & - & 0 (filled in) & $\begin{array}{l}\text { at least two staggered } \\
\text { polyadenylation sites }\end{array}$ & $\begin{array}{l}\text { confirmed by } \\
\text { Lynn Quarmby } \\
\text { (pers. comm.) }\end{array}$ \\
\hline
\end{tabular}


Table 1 Summary of FST determination. Lines in italics indicate absence of valid FST (Continued)

\begin{tabular}{|c|c|c|c|c|c|c|c|c|c|c|c|}
\hline \#3.3 & 1 & 2 & 7 & $\begin{array}{l}1015855: 1015936 \\
\text { and } \\
1015996-1016192\end{array}$ & Cre07.g319550 & $\begin{array}{l}\text { FIST C domain } \\
\text { protein }\end{array}$ & intron 1 & + & 0 (filled in) & $\begin{array}{l}\text { two staggered } \\
\text { polyadenylation sites }\end{array}$ & confirmed \\
\hline \#3.4 & 3 & 0 & & & & & & & 0 (filled in) & FAILED : FST too short (1 nt) & - \\
\hline \#3.5 & 1 & 1 & $?$ & $\begin{array}{l}\text { Chr_7:2564723- } \\
2565098 \\
\text { and other } \\
\text { locations }\end{array}$ & $\begin{array}{l}\text { genes similar } \\
\text { to Cre07.g332350 }\end{array}$ & unknown function & usually intron 1 & + & $\begin{array}{l}9 \text { (incl. } \\
\text { overhang) }\end{array}$ & $\begin{array}{l}\text { UNMAPPED: maps equally } \\
\text { well in several homologous } \\
\text { genes }\end{array}$ & - \\
\hline \#3.6 & 2 & 1 & 3 & $2440121-2440156$ & Cre03.g166950 & $\begin{array}{l}\text { PGM5, } \\
\text { phosphoglycerate } \\
\text { mutase }\end{array}$ & intron 6 & + & 0 (filled & in) + additional G & \\
\hline \multicolumn{12}{|c|}{ confirmed } \\
\hline$\# 3.7$ & 2 & 0 & & & & & & & & $\begin{array}{l}\text { FAILED: amplifies a sequence } \\
\text { from Cre } 14.9632700 \text { exon } 20 \\
\text { but the junction with the cassette } \\
\text { cannot be read }\end{array}$ & $\begin{array}{l}\text { disproved } \\
\text { (gene intact) }\end{array}$ \\
\hline \#3.8 & 3 & 1 & $?$ & $?$ & $?$ & & & & 0 (uncut) & $\begin{array}{l}\text { UNMAPPED: the } 35 \mathrm{nt} \text { FST } \\
\text { maps to several locations }\end{array}$ & - \\
\hline \#3.11 & 2 & 2 & 17 & 2083314-2083570 & Cre17.g712100 & MDAR1 & intron 7 & + & 0 (filled in) & $\begin{array}{l}\text { one FST suggests artifactual } \\
\text { splicing between end of } \\
\text { marker and exon } 8\end{array}$ & $\begin{array}{l}\text { unsure, PCR } \\
\text { failed }\end{array}$ \\
\hline \#3.12 & 2 & 1 & 10 & $1630598-1630551$ & Cre10.g429850 & $\begin{array}{l}\text { protein of unknown } \\
\text { function conserved } \\
\text { in Chlorophyceae }\end{array}$ & intron 6 & + & 0 (uncut) & $\begin{array}{l}2 \text { insertions? underneath the } \\
\text { main sequence, you can also } \\
\text { read a short FST corresponding } \\
\text { to a repeated sequence }\end{array}$ & $\begin{array}{l}\text { unsure, PCR } \\
\text { failed }\end{array}$ \\
\hline \#4.1 & 1 & 2 & 5 & $\begin{array}{l}377208-377154 \\
\text { and }-377020\end{array}$ & Cre05.g231500 & Zn-finger protein & intron 6 & + & 0 (uncut) & $\begin{array}{l}\text { two staggered } \\
\text { polyadenylation sites }\end{array}$ & confirmed \\
\hline$\# 4.2$ & 1 & 1 & 8 & $\begin{array}{l}\text { v5:4490830- } \\
4491010\end{array}$ & $\begin{array}{l}\text { Augustus__ } \\
11.2 \lg 9033 . t 1\end{array}$ & unknown function & 3' UTR & + & 0 (uncut) & $\begin{array}{l}\text { a good FST, not found in } \\
\text { version } 4 \text { genome but found } \\
\text { in three unpublished genome } \\
\text { assemblies }\end{array}$ & not tested \\
\hline$\# 4.3$ & 2 & 0 & & & & & & & & FAllED: no good sequence & - \\
\hline$\# 4.4$ & 2 & 1 & 2 & 9598215-9596562 & Cre02.g115000 & $\begin{array}{l}\text { Ribosome-binding } \\
\text { factor A }\end{array}$ & intron 4 & + & 0 (uncut) & $\begin{array}{l}\text { two staggered polyadenylation } \\
\text { sites; intron } 5 \text { is retained in } \\
\text { the chimeric } \\
\text { mRNA, but intron } 6 \\
\text { is spliced out }\end{array}$ & confirmed \\
\hline$\# 4.5$ & 3 & 0 & & & & & & & & FAllED: no good sequence & - \\
\hline \#4.6 & 2 & 2 & $?$ & $?$ & $?$ & & & & & $\begin{array}{l}\text { UNMAPPED: a } 35 \text { nt FST } \\
\text { mapping to several locations, } \\
\text { and a long one not mapping } \\
\text { at all }\end{array}$ & - \\
\hline
\end{tabular}


Table 1 Summary of FST determination. Lines in italics indicate absence of valid FST (Continued)

\begin{tabular}{|c|c|c|c|c|c|c|c|c|c|c|c|}
\hline$\# 4.8$ & 1 & 2 & 7 & $\begin{array}{l}\text { 698506-698423 } \\
\text { and }-698252\end{array}$ & $\begin{array}{l}\text { Cre07.g317300/ } \\
\text { Cre07.g317350 }\end{array}$ & $\begin{array}{l}\text { MAPKKKK1 and a } \\
\text { protein of unknown } \\
\text { function }\end{array}$ & intergenic & not applicable & 0 (uncut) & & confirmed \\
\hline$\# 4.9$ & 1 & 0 & & & & & & & & $\begin{array}{l}\text { FAILED: polyadenylation } \\
\text { starts within the marker }\end{array}$ & - \\
\hline$\# 4.10$ & 1 & 1 & 7 & $4591244-4590811$ & Cre07.g346000 & unknown function & end of $3^{\prime} U T R$ & + & & $\begin{array}{l}\text { poly-A site downstream } \\
\text { of gene model }\end{array}$ & confirmed \\
\hline$\# 4.12$ & 1 & 0 & & & & & & & & FAllED: no good sequence & \\
\hline$\# 11.1$ & & 1 & 16 & 2391524-2391584 & Cre16.g666300 & protein kinase & $\begin{array}{l}\text { upstream, } \\
\text { intergenic }\end{array}$ & not applicable & $?$ & $\begin{array}{l}\text { the PCR product cannot be } \\
\text { read in the FST (primer too } \\
\text { close to end) }\end{array}$ & $\begin{array}{l}\text { disproved } \\
\text { (gene intact) }\end{array}$ \\
\hline$\# 11.3$ & 1 & 0 & & & & & & & & $\begin{array}{l}\text { FAlLED: no marker DNA } \\
\text { in sequence }\end{array}$ & - \\
\hline$\# 11.4$ & 1 & 1 & 4 & $704462-705281$ & Cre04.g215800 & no annotation & last exon & + & 2 & & $\begin{array}{l}\text { unsure, PCR } \\
\text { failed }\end{array}$ \\
\hline$\# 11.5$ & 1 & 0 & & & & & & & & FAlLED: no match to genome & - \\
\hline$\# 14.1$ & 3 & 1 & 14 & $\begin{array}{l}\text { 2909515-2909394 } \\
\text { and 2908783- } \\
2908718\end{array}$ & Cre14g.627600 & Dynein heavy chain & $\begin{array}{l}\text { intron } 6 \text { and } \\
\text { exon } 8\end{array}$ & + & 0 & $\begin{array}{l}\text { evidence for genome } \\
\text { rearrangement or } \\
\text { aberrant splicing }\end{array}$ & $\begin{array}{l}\text { disproved } \\
\text { (gene intact) }\end{array}$ \\
\hline$\# 14.2$ & 1 & 2 & $\begin{array}{l}12 \text { and } \\
\text { other }\end{array}$ & $\begin{array}{l}\text { > a dozen } \\
\text { locations } \\
\text { (with splicing) }\end{array}$ & many & $\begin{array}{l}\text { Chlamydomonas- } \\
\text { specific kinase family }\end{array}$ & usually exon 4 & + & 0 & $\begin{array}{l}\text { UNMAPPED: too many } \\
\text { good hits }\end{array}$ & - \\
\hline$\# 14.3$ & 3 & 1 & 14 & $3326333-3326254$ & $\begin{array}{l}\text { Cre14.g630150/ } \\
\text { Cre14.g630200 }\end{array}$ & $\begin{array}{l}\text { TRAF-type zinc } \\
\text { finger protein; } \\
\text { protein of unknown } \\
\text { function conserved } \\
\text { in Volvox only }\end{array}$ & intergenic & not applicable & 0 & & $\begin{array}{l}\text { unsure, PCR } \\
\text { failed }\end{array}$ \\
\hline$\# 14.4$ & 3 & 0 & & & & & & & & FAILED: FST too short (2 nt) & - \\
\hline
\end{tabular}




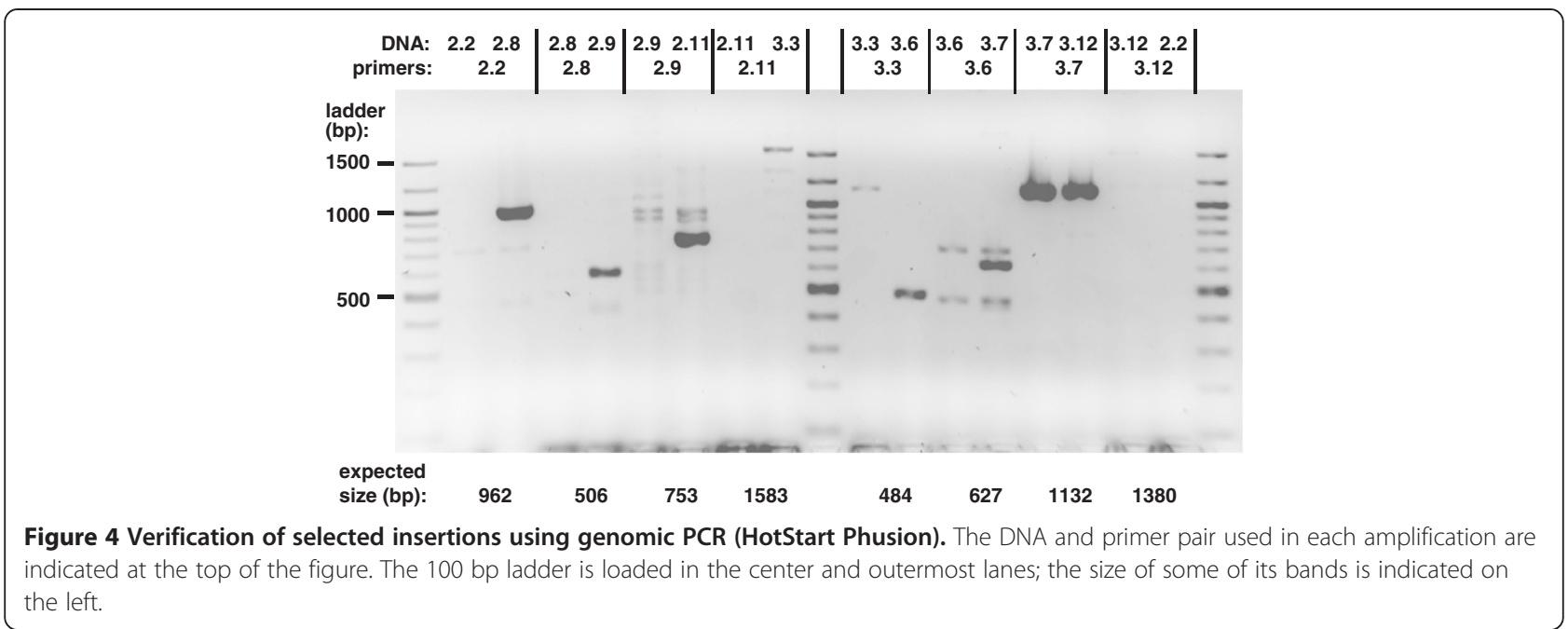

an intact copy of the gene was still present in the genome, suggesting that the FST was an artifact, or that the gene underwent duplication concomitant with cassette integration. One additional transformant that we did not check (\#3.2) was independently verified as carrying an insertion at the expected position (Lynne Quarmby, University of British Columbia, personal communication).

\section{Discussion}

\section{An efficient method for FST retrieval}

The goal of this study was to devise a simple and reliable method for identification of FSTs in Chlamydomonas. We took advantage of the serendipitous observation that transformants can be obtained using a selection marker carrying a truncated 3' UTR [12]. This suggested to us that antibiotic resistance could rely on the production of a chimeric mRNA, starting in the marker and reading into the insertion flank where cleavage and polyadenylation of the pre-mRNA would occur. Here, we have amplified such chimeric mRNAs using a simple 3'-RACE protocol [14], with only minor modifications. This allowed us to retrieve valid FSTs from $71 \%$ of the transformants we examined. Almost all of these FSTs were uniquely mappable onto the genome. In 11 of 13 cases tested, the identification of the insertion locus was corroborated by genomic PCR, i.e. no amplification was obtained in the transformant with primers flanking the insertion point. In two cases, we were unable to observe the gene interruption predicted by the FST when we analyzed the DNA of the transformants: either the FST was an artifact, or a local duplication occurred at the site of the insertion. Overall, our method compares well, in terms of ease, success rate and reliability, with other published methods. It is also quite versatile, and can be adapted to markers other than CrAadA. Recently, our method has been used with an AphVIII-containing paromomycin resistance cassette, with very satisfactory results (Jae-Hyok Lee, University of British Columbia, personal communication).

We emphasize that we intentionally limited our efforts to retrieve any particular FST, because we wanted to test the validity of the method in a medium-throughput mode. In many cases, the PCR product was submitted to Sanger sequencing without purification of the specific products. We believe that the success rate and robustness of the method can be improved, for example by exploring more RT-PCR primers or by systematically reamplifying DNA fragments when several bands are found, as suggested in [8]. However, as it stands, our 3'-RACE FST method still represents a valuable addition to the molecular biology toolkit of Chlamydomonas. Its major advantage is that it does not use degenerate primers that can make methods such as TAIL- or RESDAPCR difficult to perform in Chlamydomonas (our unpublished results). No enzyme digestion or adapter ligation is required, in contrast to GenomeWalker and Adapter-Ligation Mediated PCR, and the ability to retrieve an FST does not depend on the vicinity of any particular restriction site. Also, RNA is more abundant in the cell than DNA, allowing the use of small culture volumes. Our $20 \mathrm{ml}$ cultures yielded RNA sufficient for hundreds of reactions, so culture volumes in the $\mathrm{ml}$ range could be considered.

In its essence, our method is symmetrical to the promoter-trap experiments that have been carried out in a number of organisms including Chlamydomonas [15], where a promoterless construct randomly introduced into the genome relies on an endogenous promoter for its expression. In comparison, our 3'-RACE FST method can hit a wider diversity of sites, since all that is required 
is the presence downstream of the introduced cassette of some sequence recognizable by the PollI polymerase complex as a cleavage and polyadenylation signal, even with low efficiency. In Chlamydomonas, the main signal has been identified as TGTAA, located on average $14 \mathrm{nt}$ upstream of the polyadenylation site $[16,17]$. This simple sequence motif occurs on average every $1.5 \mathrm{~kb}$ in Chlamydomonas, but because some degeneracy is allowed, it is expected that a large fraction of the insertions would fall not too far upstream of such a sequence, allowing expression of the gene at a level sufficient for antibiotic resistance. Clearly, a TGTAA sequence is not strictly necessary to determine termination of the transcript. Only 12 of the 26 poly-A tails we recorded showed a TGTAA sequence within 22 nt upstream of the cleavage point, and while many of the others presented similar sequences fitting one of the variations observed by [17], seven did not. The native polyadenylation site of the host gene was observed in only one case. The observed degeneracy of polyadenylation signals is in line with the finding that there was no bias in favor of insertion in the 3'-UTR of genes (only 5 out of 18 mappable FSTs), as could have been feared.

Like any method, ours has its limitations. One of them is that the 3'-UTR less cassette transforms with a lower efficiency compared with a complete cassette (approximately half, see also Figure $1 B$ in [12]). But this is a moderate effect, compared to the 5 -fold reduction observed when the promoter region is omitted. By and large, it results in the generation of a sufficient number of transformants for any type of library. Indeed, most of the mutants isolated by the Grossman laboratory using their strategy of target-specific genomic PCR of pooled mutants [18] were obtained with a cassette carrying a truncated 3' UTR, the stated aim being to reduce the distance between the marker-specific primer in the CDS and the target gene. These authors also noted the possibility that chimeric mRNAs can be formed, but they rather considered it as a drawback.

A more serious limitation is that that the chimeric mRNA may be of low abundance and may contain multiple weak polyadenylation sites, thus yielding no or many faint PCR products. The sequences that we have obtained indeed vary a lot in length and quality (only the best ones for each transformant are shown in Additional file 1). With such small amounts of RNA to amplify, contamination by background bands and by DNA from other PCR reactions can also prove a severe limitation. But if high-throughput sequencing is put to use in the context of a large insertion library, then we can hope to detect even low abundance transcripts. Another limitation is that the cleavage and polyadenylation signal can occur by chance shortly after the insertion site, yielding an FST too short for mapping. Usually, however, it is expected that longer transcripts will also be produced, which could yield FSTs of sufficient length. Still, early polyadenylation has led to failure in two cases in this study. In fact, we eventually realized that the PCR product which we used was far from optimal, since it contained a TGTAA sequence 25 nt before its end. This sequence was contributed by the end of the RBCS2 CDS, where it does not function as a cleavage and polyadenylation signal. We did not seek to remove it, which in retrospect was clearly a mistake. This is another area where our protocol can easily be improved.

\section{Preferred insertion in transcribed regions}

When we examined the site of insertion of the cassette in our transformants, we realize that genes were preferentially hit, compared to intergenic regions (see Table 1). While genes are predicted to occupy $54 \%$ of the Chlamydomonas genome [19], 23 of our 28 FSTs lie within genes versus 5 in intergenic regions and transposable elements. These numbers suggests that the cassette is better expressed when it inserts into transcribed regions. Among the genes that we identified in our minicollection, several are worth noticing. PSBS3 (interrupted in transformant \#2.2) is one of three homologues of the plant PsbS gene, which has been shown to be involved in non-photochemical quenching of photosynthetic light excitation [20]. $R B F 1$, the ribosome factor $\mathrm{A}$, is also a chloroplast-targeted protein possibly involved in rRNA biogenesis. The monodehydroascorbate reductase $M D A R 1$ is probably part of the antioxidant defense system [21], while CNK2 has been shown to regulate flagellar length and cell size in Chlamydomonas [22]. Other affected genes have been proposed putative functions (a glycoside hydrolase belonging to family 32 ; the phosphoglycerate mutase PGM5; a putative transporter of the Major Facilitator Superfamilly). Others contain domains suggesting various molecular functions (protein kinase, FIST C, PAS, Zinc-finger, NAC, HRDC, SGNH hydrolase).

Interestingly, we observed a strong bias in the orientation of the cassette with respect to the interrupted gene. In 20 cases, the transcription of the cassette used the same strand as the host gene, and in only two cases was it in the opposite direction. We think that this is not due to a bias in our ability to retrieve FSTs by 3'-RACE, as Gonzalez-Ballester and co-workers, using a DNA-based method, also found an excess of sense vs. antisense orientation (31 vs. 15) [18]. Rather, we propose that a cassette inserting in opposite orientation within a transcribed gene would be subject to anti-sense effects, lowering its expression level below the resistance threshold. To improve transformant yield, it might be a good idea in the future to include inward-reading cleavage/ polyadenylation signals at both ends of the cassette. This 
would reduce the chance that transcripts from surrounding promoters read into the cassette and cause it to become silenced. We note that even if the cassette is in the sense orientation, expression of the interrupted gene is likely to be severely disrupted. Insertions lying within introns are also expected to prevent gene expression, because Chlamydomonas uses an intron definition model to splice its usually short introns [23].

\section{Modification of the DNA ends upon transformation}

It is generally assumed that transformation involves the formation of a double stranded break in the genome and its repair by non-homologous end-joining [24]. The key event is the association of the Ku70-Ku80 complex, both with the free ends of the genomic DNA and with the ends of the transforming DNA. Ku binds with high affinity to all sorts of DNA ends, and we were therefore not surprised that similar transformant yields were obtained with restriction-digested or uncut PCR products. As part of the end-joining process, the DNA ends can be modified, and we indeed observed evidence for such processes. For example, the BsiWI overhang was usually filled in, consistent with repair by a polymerase. In a few cases (\#2.1, \#3.6), untemplated nucleotides have clearly been added between the marker and the FST. Resection of the marker DNA was a concern for FST retrieval, and we were thus relieved to see that only 4 of our insertions (out of 24 scored) showed evidence for marker resection. Maximum resection was 9 nt i.e. far less than would be necessary to destroy the primer binding site. Another concern if one wants to correlate the FST with a phenotype is that the genome should not carry large deletions that would affect genes on the other side of the marker. We have not tried to sequence the other flanking sequence of our insertions, but Gonzalez-Ballester and coworkers have found that in general their cassette lacking the 3'UTR yielded no or only short genomic deletions [18].

In our experiments, we observed cases where the cassette was ligated to another copy of the transforming DNA or a fragment (see for example transformants \#2.1) at the site of insertion into the genome. Indeed, tandem cassettes insertions are quite frequent in Chlamydomonas transformation. In early experiments, we also found that carrier salmon DNA used in our initial electroporation protocol could be inserted together with the marker and thus form the FST. In experiments with digested plasmids, we have also observed that religation could involve the sticky ends generated by the restriction enzyme used (data not shown). The presence of microhomology at the end of the joined molecules is known to greatly favor end-joining [24]. All these observations lead us to recommend the use of purified PCR product, at the lowest possible concentration and with no modification or cleavage of the DNA ends.

\section{Conclusion}

We describe a new method for FST retrieval by 3' RACE in Chlamydomonas and show that it can be used with a reasonable success rate on a small number of transformants. Because any transformant obtained with a cassette lacking the 3'UTR can also be subjected to DNAbased methods for FST retrieval, as was done in ref [18], we would advise any mutant-library generation project to start with such a truncated cassette, so that both the 3'-RACE and the DNA-based methods can be used to retrieve the desired FSTs. We believe that the main limitations of our method, i.e. the overall low abundance of the chimeric mRNA and the multiplicity of weak polyadenylation sites, can be easily overcome if the power of high throughput sequencing is brought to bear. We are currently adapting our 3'-RACE FST protocol for the Illumina sequencing of a large number of mutants in parallel. We also hope that this method will be applicable not only to Chlamydomonas, but also to other organisms where it is desired to retrieve FSTs from libraries of insertional or transposon-tagged mutants.

\section{Materials and methods}

\section{Strains}

Two strains of Chlamydomonas reinhardtii have been used in this study. Strain D66 (cw15, nit2, mt+) [25] was kindly provided by $\mathrm{S}$. Lemaire and is used in many insertion libraries [18]. The walled strain JEX1 (nit1 nit2 mt-) is a $137 \mathrm{c}$ derivative generated by $\mathrm{X}$. Johnson in our laboratory [26] and screened as highly efficient in electroporation transformation. Strains were grown at $23{ }^{\circ} \mathrm{C}$ under continuous low light on TAP [1].

\section{Transformation of $C$. Reinhardtii}

The CrAadA cassette lacking the 3' UTR was amplified by PCR from pALM32 [12] with primers 70A_Up and RBCS_Dw (see primers in Additional file 2). For the control transformation (with 3' UTR), RBCS_Dw was replaced by BS_KpnDw. Nuclear transformation was performed with $1 \mu \mathrm{g}$ DNA by electroporation essentially as in [12], except that the walled strain JEX1 was electroporated at $1 \mathrm{kV}$. Carrier DNA was omitted and digestion mixtures were used without purification. Plating was done without starch on TAP plates containing 75 to $200 \mu \mathrm{m} / \mathrm{ml} \mathrm{Sp}$.

\section{Amplification of FSTs by 3'-RACE}

Total RNA was isolated using hot-phenol extraction [27], from $20 \mathrm{ml}$ cultures in $50 \mathrm{ml}$ Falcon tubes on a rotating wheel. Reverse transcription used the SuperScript III First-Strand kit from Invitrogen in a DNA Engine PCR machine (MJ research). Primer $\mathrm{Q}_{\mathrm{T}}$ was mixed with 
$5 \mu$ g RNA, incubated at $65{ }^{\circ} \mathrm{C}$ for 5 min then cooled to $55{ }^{\circ} \mathrm{C}$ over $100 \mathrm{sec}$, after which the annealed mixture was kept at $0{ }^{\circ} \mathrm{C}$. The RT-mix was added and incubation proceeded at $25{ }^{\circ} \mathrm{C}$ for $5 \mathrm{~min}$, then $50{ }^{\circ} \mathrm{C}$ for $50 \mathrm{~min}$. After inactivation at $85{ }^{\circ} \mathrm{C}(5 \mathrm{~min})$ and cooling to $0{ }^{\circ} \mathrm{C}$, RNAseH was added and left to degrade template RNA for $20 \mathrm{~min}$ at $37{ }^{\circ} \mathrm{C}$. The resulting cDNA was diluted 20-fold in TE buffer and kept at $4{ }^{\circ} \mathrm{C}$.

3'-RACE was performed as described in [14]. Touchdown PCR1 used primers Qo and CrAadA_F1. As a template, $0.2 \mu \mathrm{l}$ of a 200 -fold dilution of the cDNA was used in a $10 \mu \mathrm{l}$ reaction, using the Phusion enzyme (Finnzyme) in GC-buffer. After 5 min denaturation at $98{ }^{\circ} \mathrm{C}$, hybridization was carried out for $15 \mathrm{sec}$ at progressively decreasing temperature (from $72{ }^{\circ} \mathrm{C}$ to $60{ }^{\circ} \mathrm{C}$ over 12 cycles), then elongation proceeded for $3 \mathrm{~min}$ at $72{ }^{\circ} \mathrm{C}$. The following 22 cycles used a constant annealing temperature of $60{ }^{\circ} \mathrm{C}$, and the final elongation step was extended to $15 \mathrm{~min}$. PCR2 was carried out in a $40 \mu \mathrm{l}$ volume using the same program, with primers $\mathrm{Q}_{\mathrm{I}}$ and CrAadA_F2, and as a template $0.2 \mu \mathrm{l}$ of a 200 -fold dilution of the PCR1 product. Alternatively, primers $\mathrm{Q}_{\mathrm{T}}, \mathrm{Q}_{\mathrm{O}}$ and $\mathrm{Q}_{\mathrm{I}}$ were replaced by $\mathrm{Q}_{\mathrm{S}}, \mathrm{Q}_{\mathrm{U}}$ and $\mathrm{Q}_{\mathrm{D}}$ (see Additional file 2). Sanger sequencing of PCR products or bands cutout from agarose gels (purified using the PCR purification and QIAEX II kits from Qiagen, respectively), was performed by Eurofins (Ebersberg, Germany) using primer CrAadA_F4. Sequences were mapped using BLAST [28] to the Chlamydomonas v4 genome (http://www. phytozome.net) and its Augustus 10.2 annotation

\section{Additional files}

Additional file 1: Sequence of PCR products and FSTs obtained.

Additional file 2: Additional table : primers used in this study.

\section{Abbreviations}

FST: Flanking sequence tag; RACE: Random amplification of CDNA ends; Sp: Spectinomycin; TAlL-PCR: Thermal Asymmetric InterLaced PCR;

UTR: Untranslated region.

\section{Author's contributions}

LMC and OV both performed the experiments and wrote the manuscript. All authors read and approved the final manuscript

\section{Acknowledgements}

We thank R. Kuras and all members of the Wollman laboratory for support and advice. This work was supported by the Centre National de la Recherche Scientifique and by the University Pierre et Marie Curie [UMR 7141]. The Agence Nationale de la Recherche [grant ALGOMICS] funded LMC.

\section{Author details}

${ }^{1}$ Centre National de la Recherche Scientifique, Unité Mixte de Recherche 7141/Université Pierre et Marie Curie, Institut de Biologie Physico-Chimique, Paris 75005 , France. ${ }^{2}$ Present address : Centre National de la Recherche Scientifique, Unité Mixte de Recherche 7139/Université Pierre et Marie Curie, Station Biologique de Roscoff, Roscoff 29280, France. ${ }^{3}$ Unité Mixte de Recherche 7141/Université Pierre et Marie Curie, Institut de Biologie Physico-
Chimique Institut de Biologie Physico-Chimique, 13 rue Pierre et Marie Curie, Paris 75005, France.

Received: 2 May 2012 Accepted: 12 June 2012

Published: 26 June 2012

\section{References}

1. Harris EH: The Chlamydomonas sourcebook. San Diego, CA: Academic; 2009.

2. Galvan A, Gonzalez-Ballester D, Fernandez E: Insertional mutagenesis as a tool to study genes/functions in Chlamydomonas. Adv Exp Med Biol 2007, 616:77-89.

3. Liu YG, Whittier RF: Thermal asymmetric interlaced PCR: automatable amplification and sequencing of insert end fragments from P1 and YAC clones for chromosome walking. Genomics 1995, 25:674-681.

4. O'Malley RC, Alonso JM, Kim CJ, Leisse TJ, Ecker JR: An adapter ligationmediated PCR method for high-throughput mapping of T-DNA inserts in the Arabidopsis genome. Nat Protoc 2007, 2:2910-2917.

5. Thole V, Alves SC, Worland B, Bevan MW, Vain P: A protocol for efficiently retrieving and characterizing flanking sequence tags (FSTs) in Brachypodium distachyon T-DNA insertional mutants. Nat Protoc 2009, 4:650-661.

6. Dent RM, Han M, Niyogi KK: Functional genomics of plant photosynthesis in the fast lane using Chlamydomonas reinhardtii. Trends Plant Sci 2001, 6:364-371.

7. Tolleter D, Ghysels B, Alric J, Petroutsos D, Tolstygina I, Krawietz D, Happe T, Auroy P, Adriano JM, Beyly A, et al: Control of hydrogen photoproduction by the proton gradient generated by cyclic electron flow in Chlamydomonas reinhardtii. Plant Cell 2011, 23:2619-2630.

8. Gonzalez-Ballester D, de Montaigu A, Galvan A, Fernandez E: Restriction enzyme site-directed amplification PCR: a tool to identify regions flanking a marker DNA. Anal Biochem 2005, 340:330-335.

9. Tan G, Gao Y, Shi M, Zhang X, He S, Chen Z, An C: SiteFinding-PCR: a simple and efficient PCR method for chromosome walking. Nucleic Acids Res 2005, 33:e122.

10. Philipps G, Krawietz D, Hemschemeier A, Happe T: A pyruvate formate lyase-deficient Chlamydomonas reinhardtii strain provides evidence for a link between fermentation and hydrogen production in green algae. Plant J 2011, 66:330-340.

11. Pollock SV, Colombo SL, Prout DL Jr, Godfrey AC, Moroney JV: Rubisco activase is required for optimal photosynthesis in the green alga Chlamydomonas reinhardtii in a low- $\mathrm{CO}(2)$ atmosphere. Plant Physiol 2003, 133:1854-1861.

12. Meslet-Cladiere L, Vallon O: Novel Shuttle Markers for Nuclear Transformation of the Green Alga Chlamydomonas reinhardtii. Eukaryot Cell 2011, 10:1670-1678.

13. Schroda M, Beck CF, Vallon O: Sequence elements within an HSP70 promoter counteract transcriptional transgene silencing in Chlamydomonas. Plant J 2002, 31:445-455.

14. Scotto-Lavino E, Du G, Frohman MA: 3' end cDNA amplification using classic RACE. Nat Protoc 2006, 1:2742-2745.

15. Haring MA, Beck CF: A promoter trap for Chlamydomonas reinhardtii: development of a gene cloning method using 5' RACE-based probes. Plant J 1997, 11:1341-1348.

16. Silflow CD, Chisholm RL, Conner TW, Ranum LP: The two alpha-tubulin genes of Chlamydomonas reinhardi code for slightly different proteins. Mol Cell Biol 1985, 5:2389-2398.

17. Shen Y, Liu Y, Liu L, Liang C, Li QQ: Unique features of nuclear mRNA poly (A) signals and alternative polyadenylation in Chlamydomonas reinhardtii. Genetics 2008, 179:167-176.

18. Gonzalez-Ballester D, Pootakham W, Mus F, Yang W, Catalanotti C, Magneschi L, de Montaigu A, Higuera JJ, Prior M, Galvan A, et al: Reverse genetics in Chlamydomonas: a platform for isolating insertional mutants. Plant Methods 2011, 7:24

19. Merchant SS, Prochnik SE, Vallon O, Harris EH, Karpowicz SJ, Witman GB, Terry A, Salamov A, Fritz-Laylin LK, Marechal-Drouard L, et al: The Chlamydomonas genome reveals the evolution of key animal and plant functions. Science 2007, 318:245-250.

20. Li XP, Bjorkman O, Shih C, Grossman AR, Rosenquist M, Jansson S, Niyogi KK: A pigment-binding protein essential for regulation of photosynthetic light harvesting. Nature 2000, 403:391-395. 
21. Gill SS, Tuteja N: Reactive oxygen species and antioxidant machinery in abiotic stress tolerance in crop plants. Plant Physiol Biochem 2010, 48:909-930.

22. Bradley BA, Quarmby LM: A NIMA-related kinase, Cnk2p, regulates both fla3gellar length and cell size in Chlamydomonas. J Cell Sci 2005, 118:3317-3326.

23. Labadorf A, Link A, Rogers MF, Thomas J, Reddy AS, Ben-Hur A: Genome-wide analysis of alternative splicing in Chlamydomonas reinhardtii. BMC Genomics 2010, 11:114.

24. Lieber MR: The mechanism of double-strand DNA break repair by the nonhomologous DNA end-joining pathway. Annu Rev Biochem 2010, 79:181-211.

25. Schnell RA, Lefebvre PA: Isolation of the Chlamydomonas regulatory gene NIT2 by transposon tagging. Genetics 1993, 134:737-747.

26. Houille-Vernes L, Rappaport F, Wollman FA, Alric J, Johnson X: Plastid terminal oxidase 2 (PTOX2) is the major oxidase involved in chlororespiration in Chlamydomonas. Proc Natl Acad Sci U S A 2011, 108:20820-20825.

27. Drapier D, Suzuki H, Levy H, Rimbault B, Kindle KL, Stern DBWollman FA: The chloroplast atpA gene cluster in Chlamydomonas reinhardtii. Functional analysis of a polycistronic transcription unit. Plant Physiol 1998, 117:629-641.

28. Altschul SF, Madden TL, Schaffer AA, Zhang J, Zhang Z, Miller W, Lipman DJ: Gapped BLAST and PSI-BLAST: a new generation of protein database search programs. Nucleic Acids Res 1997, 25:3389-3402.

doi:10.1186/1746-4811-8-21

Cite this article as: Meslet-Cladière and Vallon: A new method to identify flanking sequence tags in chlamydomonas using 3'-RACE. Plant Methods 2012 8:21.

\section{Submit your next manuscript to BioMed Central and take full advantage of:}

- Convenient online submission

- Thorough peer review

- No space constraints or color figure charges

- Immediate publication on acceptance

- Inclusion in PubMed, CAS, Scopus and Google Scholar

- Research which is freely available for redistribution 